\title{
Carboxymethylated Pulp as Starting Point to Prepare Hydroxypropylmethyl Cellulose with Enhanced Gel Rheological Properties in an Aqueous Medium
}

\author{
Othman Hamed, ${ }^{\mathrm{a}, *}$ Rana Al-Kerm, ${ }^{\mathrm{a}}$ Rola Al-Kerm, ${ }^{\mathrm{a}}$ Hisham Qrareya, ${ }^{\mathrm{b}}$ Abdalhadi \\ Deghles, ${ }^{\mathrm{c}}$ and Omar Dagdag ${ }^{\mathrm{d}}$
}

\begin{abstract}
Hydroxypropyl methylcellulose in an aqueous solution upon heating tends to undergo thermal gelation, where the polymer chains form a network and precipitate from solution. This occurs at a temperature known as thermal gelation point. Polymer precipitation causes a significant drop in the shear viscosity. This could be a disadvantage in a hot environment or in applications were heat is applied. In this work, a hydroxypropylmethyl cellulose (HPMC) was formed that undergoes thermal gelation with no polymer precipitation and with enhanced rheological properties. The target HPMC was prepared from wood pulp with a low content of carboxymethyl groups. The produced hydroxypropyl methylcellulose (CMHPMC) derivative showed unique physical properties that are not achievable with typical hydroxypropyl methylcellulose. The thermal gelation temperature of an aqueous solution of CMHPMC was increased from $55^{\circ} \mathrm{C}$ for commercial HPMC to $85{ }^{\circ} \mathrm{C}$ for CMHPMC. A substitution level of carboxymethylation that led to an HPMC with a thermal gelation and with no precipitation was determined to be a 0.15 of carboxyl groups per anhydroglucose repeat unit. In addition, the carboxymethylated pulp showed an enhanced reactivity towards etherification reactions.
\end{abstract}

Keyword: Cellulose; Carboxymethyl cellulose; Hydroxypropyl methyl; Cellulose; Rheolog; Cuene IV; Thermal gelation

Contact information: a: An-Najah National University, P. O. Box 7, Nablus, West Bank zip code Palestinian Territories; b: Arab American University- Palestine (AAUP), P. O. Box 240, Jenin, West Bank zip code Palestinian Territories; c: Graduate Studies Department, Al-Istiqlal University, Ariha zip code Palestinian Territories; d: Laboratory of Industrial Technologies and Services (EMEL), Department of Process Engineering, Height School of Technology, Sidi Mohammed Ben Abdallah University, P.O. Box 2427, Fez 30000 Morocco;

* Corresponding authors: ohamed@najah.edu

\section{INTRODUCTION}

The chemical modification of cellulose in order to make new products for commercial applications is well documented in the literature (Petzold-Welcke et al. 2009; Siro et al. 2010; Heinze and Liebert 2012; Heinze et al. 2012; Akindoyo et al. 2016; Abushammala and Mao 2019). The chemical modification of pulp with the aim of increasing the accessibility of the hydroxyl groups in cellulose to reactants is a recent challenge in the field of cellulose chemistry and is of great importance in terms of new product development. Few publications have covered such a subject. Current literature has reported three methods for enhancing cellulose accessibility: mechanical, chemical, and enzymatic. The mechanical method entails subjecting cellulose pulp to a mechanical action to disrupt the interfibrillar bonds. This tends to increase the reactive surface area of the cellulose pulp, thus enhancing the accessibility of the cellulose (Krässig 1993). Several 
other studies in the area of mechanical treatment reported using a combination of mechanical treatments with other treatments (Isogai et al. 1992; Zhao et al. 2006).

The chemical method entails the treatment of cellulose with a swelling reagent that causes the hydrogen bonds to break, thus disrupting the cellulose's ordered regions. As a result, the cellulose structure becomes more accessible (Mantanis et al. 1995). Various solvents and reagents, e.g., sodium hydroxide (Iovleva et al. 1996; Bochek 2003) and a combination of sodium hydroxide and urea (Kunze and Fink 2005), were reported for this purpose.

Enzymes also have been used to increase the accessibility of cellulose to chemicals; it has been shown that cellulases increase the reactivity of the dissolving pulps (Rahkamo et al. 1996; Bajpai 1999; Cao and Tan 2006; Engström et al. 2006). The chemical modification the authors presented in this work involves treating the pulp with reagents that add value to the pulp without destroying its native properties. Among the types of modified pulps that are examples of this are pulps partially treated with propylene oxide (Henriksson et al. 2005) and pulps pre-treated with enzymes (Sango et al. 2018) In another approach, cellulose accessibility was achieved via the treatment of cellulosic pulp with a sodium hydroxide solution and alkylene oxide to produce hydroxyethylated pulp with a low degree of substitution (Henriksson et al. 2005).

The present work provides wood pulp with enhanced reactivity so that it can be converted to cellulose ether with enhanced rheological properties. Cellulose ether derivatives have been important commercial products for many years. They are the most widely used cellulose derivatives in the food, pharmaceutical, and construction industries (Siro et al. 2010; Tosh 2014; Arca et al. 2018). Cellulose ethers are also used as functional additives that impart water retention or improved open time properties to tile mortar, tape joint compounds, and stucco. In the extrusion of concrete panels or catalytic converter substrates, cellulose ethers give lubricity and smooth surfaces during the extrusion. In cases where elevated temperatures are encountered, cellulose ethers containing a methoxyl substitution, e.g., hydroxypropylmethylcellulose (HPMC) or methylcellulose (MC) exhibit a characteristic temperature at which a gel or network structure is formed, causing the polymer to precipitate from solution. The temperature where the thermal gelation occurs then precipitation is known as the thermal gelation temperature (Silva et al. 2008). This property considered a disadvantage as it limits the use of cellulose ethers to cooler climates or lower product processing temperatures.

Hydroxyethyl cellulose (HEC) and carboxymethyl cellulose (CMC) do not possess a thermal gelation temperature, since these cellulose ethers are hydrophilic enough that the polymer remains solvated as the temperature increases. Both polymers are known to have high water retention properties. The thermal gelation temperature depends on the polymer molar mass, degree of substitution (DS) of the methyl group per anhydroglucose repeat unit, as well as the presence and degree of any other alkoxyl substituent (Sarkar 1977; Lin 2002). The nonionic characteristics of HPMC limit many of its uses to cooler climates or lower product processing temperatures. The ability to raise the thermal gelation temperature of methyl cellulose or HPMC-based polymers in general, without sacrificing its water retention properties, would provide a level of performance not currently present in the marketplace for this class of cellulose ethers. One way of overcoming this is by preparing HPMC from cellulose with some ionic characteristics. Carboxymethylated pulp (CM-pulp) with a low DS was chosen as a starting material to prepare HPMC with slightly ionic characteristics and higher thermal gelation temperature. 
In the present study, several methods of preparing carboxymethylcellulose (CMC) with a low DS (0.04 to 0.4) from Ethenier-F-HV (obtained from Rayonier Advanced Materials) and its conversion to CMHPMC are reported. Selective physical properties of HPMC and the CMHPMC derivative were investigated.

\section{EXPERIMENTAL}

\section{Materials}

All reagents used in this project were purchased from Sigma-Aldrich (St. Louis, MO) and used as received. The reagents include monochloroacetic acid, chloromethane, ethylene oxide, and others shown below in the experimental part. All reagents used were analytical grade, and deionized water was used in this work. Ethenier-F-HV pulp was the starting material for each experiment. The Ethenier-HV pulp was produced by Rayonier Advanced Materials (Jacksonville, FL) using the sulfite process (Cuene I.V. $=11.18 \mathrm{dL} / \mathrm{g}$, ISO brightness $=90 \%$, dichloromethane extracts $=0.02 \%$, and S10-S18 $=0.8 \%$ ).

\section{Methods}

The infrared spectra were recorded using a Nicolet 6700 Fourier transform infrared (FT-IR) spectrometer equipped with the Smart Split Pea micro-ATR accessory (which had a diamond ATR crystal). The following parameters were used: a resolution of $4 \mathrm{~cm}^{-1}$, a spectral range of $400 \mathrm{~cm}^{-1}$ to $4000 \mathrm{~cm}^{-1}$, and 64 scans.

The viscosity measurements of the cellulose ether solution were carried out using a Brookfield viscometer (Brookfield Rvdv-Ii+Cp Digital Viscometer). The pulp viscosity was determined according to ISO standard 5351-1 (2003), which involved the dissolution of the pulp in an aqueous solution of copper ethylene diamine using a Cannon-Fenske viscometer. The thermal gelation temperature was determined using a Haake RS100 rheometer, and the solution clarity was determined via visual inspection.

\section{Preparation of the carboxymethylated pulp}

Carboxymethylcellulose (CMC) is usually produced by reacting cellulose treated with sodium hydroxide (alkaline cellulose) with monochloroacetic acid (MCA) or sodium salt in aqueous or organic solvents, e.g., isopropyl alcohol. The following experiments summarize the methods used to prepare the CM-pulps with low degrees of substitution.

\section{Procedure A}

A sample of Ethenier-F-HV pulp (81.0 g, oven dried weight (OD)) was suspended in a solution of $\mathrm{NaOH}$ with various concentrations, which ranged from $15.0 \mathrm{wt} \%$ to 20.0 $\mathrm{wt} \%(1.44 \mathrm{~L})$ and MCA $(5.0 \mathrm{wt} \%)$. The mixture was mechanically stirred at room temperature for $10 \mathrm{~min}$, and the excess solution (of $\mathrm{NaOH}$ and MCA) was removed via centrifugation for $10 \mathrm{~min}(2500 \mathrm{rpm})$, of which the total amount of excess solution collected was $167.0 \mathrm{~g}$ of $\mathrm{NaOH}$ and MCA. The treated pulp was then transferred to heavy duty plastic containers, flushed with nitrogen for $1 \mathrm{~min}$, sealed, and placed in a heated roller oven for $30 \mathrm{~min}$ at $70{ }^{\circ} \mathrm{C}$. The reaction was then quenched via the addition of water $(2.0 \mathrm{~L})$ and subjected to suction filtration.

The treated pulp was then processed at ambient temperatures by slurring in water, followed by recovery and numerous water washes in a Buchner funnel. The collected pulp was then re-slurried in water and acidified to a $\mathrm{pH}$ of 4.0 to 4.5 with a diluted sulfuric acid 
solution. Then, the pulp solution was stirred for $15 \mathrm{~min}$, before recovery via suction filtration followed with several water washes. The weight of the recovered pulp was 72.8 g (a $90.0 \%$ yield).

\section{Procedure B}

The following procedure was used to prepare CM-pulp with a DS of 0.07 to 0.15 . A solution of MCA (46.8 $\mathrm{g}$ in $1.0 \mathrm{~L}$ of $\mathrm{H}_{2} \mathrm{O}$ ) was added to a pulp sample $(81.0 \mathrm{~g}$, OD) at room temperature and dispersed with a spatula. After standing for $5 \mathrm{~min}$, a $\mathrm{NaOH}$ solution $(1 \mathrm{~L}, 17.5 \%)$ at various temperatures $\left(30\right.$ to $\left.40{ }^{\circ} \mathrm{C}\right)$ was added to the slurry, mechanically mixed for $10 \mathrm{~min}$, and then centrifuged for $10 \mathrm{~min}$ at $2500 \mathrm{rpm}$ (the total amount of excess solution collected was $166.5 \mathrm{~g}$ ). The treated pulp was then transferred to heavy-duty plastic containers, flushed with nitrogen for $1 \mathrm{~min}$, sealed, and then placed in a heated roller oven for $30 \mathrm{~min}$ at $70{ }^{\circ} \mathrm{C}$. The reaction was then quenched via the addition of water $(2.0 \mathrm{~L})$ and subjected to suction filtration.

The treated pulp was then processed at ambient temperatures by slurring in water, followed by recovery and numerous water washes in a Buchner funnel. The collected pulp was then re-slurried in water and acidified to a $\mathrm{pH}$ of 4.0 to 4.5 with a diluted sulfuric acid solution. Then, the pulp solution was stirred for $15 \mathrm{~min}$, before recovery via suction filtration followed with several water washes. The weight of recovered pulp was $71.7 \mathrm{~g}$ (88.5\% yield).

\section{Procedure C}

A slurry of pulp (20.0 g, OD) in a $\mathrm{NaOH}$ solution (16\%) at a $6.0 \%$ consistency was mixed at room temperature for $15 \mathrm{~min}$. The excess $\mathrm{NaOH}$ was removed by filtration (the total amount removed was $70 \mathrm{~g}$ to $74 \mathrm{~g}$ ). The treated pulp was spread in a tray, and various amounts of MCA in water $(50.0 \mathrm{~mL})$ was applied onto the pulp via spraying. The pulp was shredded using a Waring 4.0 liter Blender CB15V for $30 \mathrm{sec}$, then transferred to heavy duty plastic containers, flushed with nitrogen for $1 \mathrm{~min}$, sealed, and then placed in a heated roller oven for $30 \mathrm{~min}$ at $70{ }^{\circ} \mathrm{C}$. The reaction was then quenched via the addition of water $(2.0 \mathrm{~L})$ and subjected to suction filtration.

The treated pulp was then processed at ambient temperatures by slurrying in water, followed by recovery and numerous water washes in a Buchner funnel. The collected pulp was then re-slurried in water and acidified to a $\mathrm{pH}$ of 4.0 to 4.5 with a diluted sulfuric acid solution. Then, the pulp solution was stirred for $15 \mathrm{~min}$, before recovery via suction filtration followed with several water washes. The weight of the recovered pulp was 18.4 g $(90.0 \%$ yield $)$.

\section{Procedure D}

The following procedure was used to prepare CM-pulp with a DS of 0.04 to 0.4 . A slurry of pulp $(20.0 \mathrm{~g}, \mathrm{OD})$ in a $\mathrm{NaOH}$ solution $(16 \%)$ at a $6.0 \%$ consistency was mixed at room temperature for $15 \mathrm{~min}$. The excess $\mathrm{NaOH}$ was removed by filtration (the total amount removed was 70 to $74 \mathrm{~g}$ ). The treated pulp was spread in a tray, and various amounts of MCA in isopropyl alcohol $(100 \mathrm{~mL}, 79.0 \mathrm{~g})$ was applied onto the pulp via spraying. The pulp was then shredded using a Waring 4.0-liter Blender CB15V for $30 \mathrm{sec}$, then transferred to heavy duty plastic containers, flushed with nitrogen for $1 \mathrm{~min}$, sealed, and then placed in a heated roller oven for $30 \mathrm{~min}$ at $70{ }^{\circ} \mathrm{C}$. The reaction was then quenched via the addition of water $(2.0 \mathrm{~L})$ and subjected to suction filtration. 
The treated pulp was then processed at ambient temperatures by slurrying in water, followed by recovery and numerous water washes in a Buchner funnel. The collected pulp was then re-slurried in water and acidified to a $\mathrm{pH}$ of 4.0 to 4.5 with a diluted sulfuric acid solution. Then, the pulp solution was stirred for $15 \mathrm{~min}$, before recovery via suction filtration followed with several water washes. The weight of the recovered pulp was 18.8 $\mathrm{g}(94.0 \%$ yield $)$.

\section{Preparation of the cellulose ether solution}

A sample of the prepared cellulose ether CMHPMC was ground using a Wiley mill through a $0.5 \mathrm{~mm}$ screen. A cellulose ether solution (2.0\%) was prepared by slowly adding, over a period of $30 \mathrm{sec}$, a $2.0 \mathrm{~g}$ sample of ground CMHPMC to $198.0 \mathrm{~mL}$ of boiling distilled water. The suspension was slowly cooled down to room temperature while being stirred. Then the solution was placed in the refrigerator for approximately $12 \mathrm{hr}$.

The viscosity of the produced gel was measured using a Brookfield Rvdv-Ii+Cp Digital Viscometer (a spindle number of 6, a rpm of 5, and a temperature of $22{ }^{\circ} \mathrm{C}$ ).

\section{Insolubles}

A sample ( $2 \%$ by weight) of CMHPMC gel in water $(20.0 \mathrm{~g})$ was diluted with distilled water up to $200.0 \mathrm{~g}$. The mixture was mixed for $20 \mathrm{~min}$ and then centrifuged at $4500 \mathrm{rpm}$ for $10 \mathrm{~min}$. The centrifuging was carried out using a 16F6-28 Eppendorf centrifuge (6 x 60/30 mL rotors) (Eppendorf Belgium N.V./S.A, Aarschot, Belgium). The solution was decanted, and then the residue was washed with distilled water $(100.0 \mathrm{~mL})$, stirred, and centrifuged at $4500 \mathrm{rpm}$ for $10 \mathrm{~min}$. The washing procedure was repeated 3 times. Then, the residue was place in a pre-weighted glass vial and dried at $105^{\circ} \mathrm{C}$ for approximately $3 \mathrm{~h}$.

\section{Turbidity}

The gel clarity of the $2.0 \%$ solution was optically measured using a turbidimeter Ration XR (HACH, Loveland, CO).

\section{Carboxymethyl content}

Two different procedures were used to determine the carboxyl content of the CMpulp. For pulp samples with a low carboxyl content, TAPPI standard T237 om-08 (2008) was followed. For pulp samples containing carboxylmethyl groups greater than 0.10 D. S., the following procedure was followed:

The CM-pulp (2.000 g) was converted into its acid form by soaking it in $5 \%$ acetic acid solution in water $(300 \mathrm{~mL})$, for at least $3 \mathrm{~h}$. The treated CM-pulp was then washed free from the salts and acid with distilled water ( 5 times with $300 \mathrm{~mL}$ ), transferred to a beaker $(600 \mathrm{~mL})$, and $\mathrm{NaOH}$ was added $(100 \mathrm{~mL}, 0.05 \mathrm{~N})$. After sitting for $3 \mathrm{~h}$ in the $\mathrm{NaOH}$ solution, the excess $\mathrm{NaOH}$ was back titrated with $0.05 \mathrm{~N} \mathrm{HCl}$ to a phenolphthalein end point ( $\mathrm{pH}=8.3$, as determined by a $\mathrm{pH}$ meter).

The carboxyl content was calculated according to Eq. 1,

Carboxyl content $(\mathrm{meq} / \mathrm{kg})=\left[\mathrm{meq}\right.$ of $\mathrm{NaOH}\left(\mathrm{V}_{\mathrm{NaOH}} \times \mathrm{N}_{\mathrm{NAOH}}\right)-$ meq of $\mathrm{HCl}$

x $\left(V_{\mathrm{HCl}}\right.$ x $\left.\left.N_{\mathrm{HCl}}\right)\right]$ x $1000(\mathrm{~g} / \mathrm{kg}) /$ wt. of CMC pulp $(\mathrm{g})$

where meq is the milliequivalent, $V$ is the volume, and $N$ is the normality

The degree of substitution was calculated according to Eq. 1, 
Degree of Substitution DS $=[$ Carboxyl content (meq $/ \mathrm{kg}) \times 162(\mathrm{MM}$ of
anhydroglucose repeat unit) $] / 1 \times 10^{6}$

where meq is the milliequivalents and MM is the molar mass.

\section{Carboxymethyl hydroxypropyl methylcellulose (CMHPMC) from CM-pulp}

The etherification of CM-pulp with various DS was carried out in a horizontal Parr reactor (Parr Instrument Company, Moline, IL). The CM-pulp was ground through a 20mesh screen using a Wiley mill and the etherification reaction was carried out on alkali cellulose with methyl chloride and propylene oxide as shown below.

The CM-pulp ((30.0 g) $0.187 \mathrm{~mol}$ of anhydroglucose repeat unit) was introduced into a $2 \mathrm{~L}$ horizontal Parr reactor. The reactor was purged four times with nitrogen, followed by evacuating the reactor. After completely removing the air from the reactor, the sample was treated with a caustic solution $(75.0 \mathrm{~g}, 50 \%)$ while being agitated. The caustic solution was added dropwise over a period of $30 \mathrm{~min}$ through Teflon tubing from a sample cylinder placed under pressure. The etherification reagents, propylene oxide $(10.0 \mathrm{~g})$, and chloromethane $(65.0 \mathrm{~g})$, were then slowly added to the reactor through Teflon tubing from sample cylinders. The reaction mixture was heated to $80{ }^{\circ} \mathrm{C}$ over a period of $2 \mathrm{~h}$ and maintained at $80^{\circ} \mathrm{C}$ for $1 \mathrm{~h}$. At the end of the etherification process, the product was washed sequentially (each wash was $1.0 \mathrm{~L}$ ) with the following: hot water (at a temperature greater than $90{ }^{\circ} \mathrm{C}$ ), a hot solution of acetic acid $(10 \%$, for neutralization), and then hot water again (to remove the salt from the product), before being dried in an $80{ }^{\circ} \mathrm{C}$ oven. By carefully following the etherification reaction (by measuring the reaction temperature and the pressure with time), it was noticed that the CM-pulp with a DS of 0.15 was more reactive than other CM-pulps with a lower DS (an unusual exothermic reaction was observed). This could be related to the enhanced reactivity of the CM-pulp due to the presence of the carboxymethyl groups. Due to this unusual result, and in order to optimize the etherification process of the CM-pulp, the reaction was repeated at different molar ratios of caustic solution to pulp. This was carried out to preserve the pulp's intrinsic viscosity (IV) without affecting the DS.

\section{Thermal gelation temperature}

A Haake RS100 rheometer at a constant shear rate and the deflection angle in oscillatory mode was programmed for a temperature ramp at a constant heating rate. The complex viscosity, storage modulus, and loss modulus were recorded as a function of the temperature. The inflection point, where the three parameters rapidly decrease with temperature, was the onset of cellulose ether precipitation from solution. The minimum in the storage modulus corresponds to the thermal gelation temperature, where a network structure begins to form due to the associative nature of the methoxyl groups that have become desolvated as the temperature increases.

\section{Rheology and the molecular weight distribution of cellulose ethers}

Cellulose ether CMHPMC solutions ( $2 \mathrm{wt} . \%$ in water) were prepared and run on the Haake RS100 rheometer using the oscillatory frequency sweep mode at several temperatures. The best sensitivity to detect the substructures in the molecular weight distribution curve was found using a parallel plate arrangement with a $60 \mathrm{~mm}$ diameter plate. A $15 \%$ strain, with a frequency range of $0.10 \mathrm{~Hz}$ to $25.1 \mathrm{~Hz}$, was covered from 10 ${ }^{\circ} \mathrm{C}$ to $25^{\circ} \mathrm{C}$ in $5^{\circ} \mathrm{C}$ increments. The complex viscosity, storage modulus, and loss modulus 
were recorded as a function of frequency, i.e., the shear rate. The data at all tested temperatures was imported into the Polysoft program to generate the qualitative molecular weight distributions. Sample comparisons were generally made at a reference temperature of $15^{\circ} \mathrm{C}$.

\section{RESULTS AND DISCUSSION}

Carboxymethylated pulp (CM-pulp) with a low degree of substitution was prepared by reacting never dried pulp with sodium chloroacetate (MCA) and sodium hydroxide, as shown in Fig. 1. The effects of changing the amount of $\mathrm{NaOH}$ and $\mathrm{MCA}$, as well as the reaction temperature and solvent, on the D. S. and IV based on cuene solutions of the produced CM-pulp were carefully evaluated. Sodium hydroxide played two roles: (1) it had the effect of disrupting the hydrogen bonding, hence making the hydroxyl groups accessible for interaction with reagents, and (2) it also activated the hydroxyl group for nucleophile substitution. The degree of substitution was highly affected by the concentration of the sodium hydroxide solution, the quantity of MCA, and the type of solvent present. The goal in this study was to develop a convenient method for preparing CM-pulp with a low DS, and then converting it to CMHPMC with unique physical properties for industrial applications.
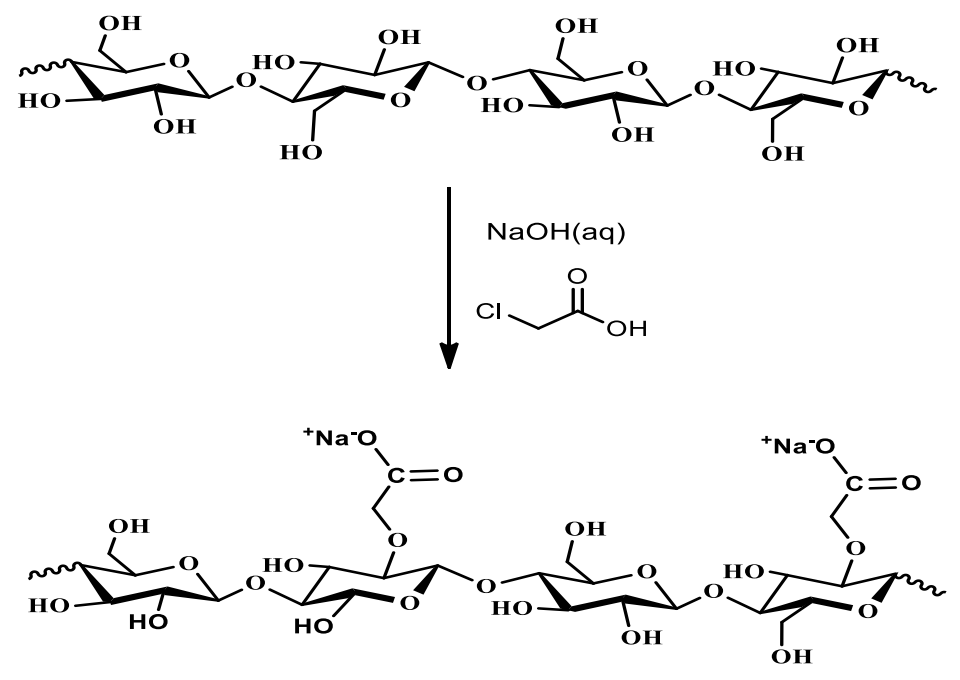

Fig. 1. Conversion of pulp to CM-pulp

\section{Carboxymethylated Pulp}

Several preparation methods were evaluated for making CM-pulp with a low DS. In method $\mathrm{A}$, carboxymethylation was performed in water at a constant temperature, with a constant amount of MCA, and at various concentrations of $\mathrm{NaOH}$. Despite the large quantities of MCA and $\mathrm{NaOH}$ used, CM-pulps with a low carboxyl content were obtained, as shown in Table 1. Attempts to attain pulp with a higher DS under these reaction conditions were unsuccessful. The low DS could be related to the competing side reaction between $\mathrm{NaOH}$ and MCA (as shown in Fig. 2), which mainly occurs when water is present and increases with increasing the concentration of $\mathrm{NaOH}$. The results showed some reduction in the pulp's IV. 


$$
\mathrm{CICH}_{2} \mathrm{CO}_{2} \mathrm{H}+2 \mathrm{NaOH}_{(\mathrm{aq})} \longrightarrow \mathrm{HOCH}_{2} \mathrm{CO}_{2}{ }^{-} \mathrm{Na}^{+}+\mathrm{NaCl}
$$

Fig. 2. Side reaction between $\mathrm{NaOH}$ and $\mathrm{MCA}$

Table 1. Effect of Increasing the Amount of $\mathrm{NaOH}$ on the Carboxyl Content of CM-Pulp in the Presence of a Constant Amount of MCA

\begin{tabular}{|c|c|c|c|}
\hline $\mathrm{NaOH}(\%)$ & $\mathrm{NaOH}$ in Pulp (\%) & Degree of Substitution & $\begin{array}{c}\text { Cuene IV } \\
(\mathrm{d} / \mathrm{g})\end{array}$ \\
\hline 0.0 & - & - & 11.2 \\
\hline 15.0 & 31.0 & 0.041 & 10.96 \\
\hline 17.5 & 36.0 & 0.029 & 10.07 \\
\hline 20.0 & 41.0 & 0.0086 & 9.63 \\
\hline Note: Pulp weight = 81.0 g (OD)
\end{tabular}

Procedure B involved impregnating the pulp in a MCA solution for $5 \mathrm{~min}$, then adding a $\mathrm{NaOH}$ solution at various temperatures. The results are shown in Table 2. A CMpulp with a higher DS was obtained by this method. In addition, the DS of the CM-pulp increased as the temperature of the $\mathrm{NaOH}$ solution increased. However, the IV of the CMpulp decreased as the temperature increased. The reduction in the IV could be related to the degradation effect of $\mathrm{NaOH}$ on the pulp as the temperature of the $\mathrm{NaOH}$ solution increased. The degradation of the CM-pulp was reduced by purging the MCA solution with nitrogen as well as by carrying out the reaction under a blanket of nitrogen (as shown in Table 2).

Table 2. Effect of Increasing the Temperature of the $\mathrm{NaOH}$ Solution on the Carboxyl Contents and the Cuene IV of CM-pulp at a Constant Amount of MCA

\begin{tabular}{|c|c|c|c|}
\hline Temperature of $\mathrm{NaOH}^{1}\left({ }^{\circ} \mathrm{C}\right)$ & $\begin{array}{c}\text { Carboxyl Content } \\
(\mathrm{meq} / \mathrm{Kg})\end{array}$ & $\begin{array}{c}\text { Degree of } \\
\text { Substitution }\end{array}$ & Cuene IV (d/g) \\
\hline 20 & 480.3 & 0.078 & 9.69 \\
\hline 40 & 985.0 & 0.16 & 8.45 \\
\hline $30^{2}$ & 986.0 & 0.16 & 10.10 \\
\hline $40^{2}$ & 826.0 & 0.14 & 9.74 \\
\hline \multicolumn{2}{|l|}{ The wt.\% of $\mathrm{NaOH}$ on pulp in all runs is $36 \%$} \\
2. These reactions were carried out under a blanket of $\mathrm{N}_{2}$ atmosphere \\
\hline
\end{tabular}

In an attempt to reproduce the above results without the treatment of pulp with excess $\mathrm{NaOH}$ and $\mathrm{MCA}$, Procedure $\mathrm{B}$ was repeated by applying only the total recovered amount of MCA and $\mathrm{NaOH}$ to the pulp samples, followed by shredding for $30 \mathrm{~s}$, as shown in procedure $\mathrm{C}$. In this procedure (procedure $\mathrm{C}$ ), the pulp was first pre-steeped in $\mathrm{NaOH}$ (16\%) for $10 \mathrm{~min}$, filtered to a total recovery amount of $70 \mathrm{~g}$ to $74 \mathrm{~g}$, then a MCA solution in water was applied onto the pulp via spraying. A DS of 0.311 was obtained by using procedure C. From these results it could be concluded that the mixing step (the pulp treatment with excess $\mathrm{NaOH}$ and MCA prior to centrifuging) was the controlling factor in the DS of the produced pulp. The IV of the produced CM-pulp ranged from $9.8 \mathrm{~d} / \mathrm{g}$ to 10.1 $\mathrm{d} / \mathrm{g}$. 
Table 3. Effect of Increasing the Amount of MCA on the D. S. of the CM-pulp at a Constant Amount of $\mathrm{NaOH}$ and a Reaction Time of (1 h)

\begin{tabular}{|c|c|c|c|c|}
\hline $\begin{array}{c}\text { Weight of MCA } \\
(\mathrm{g})\end{array}$ & $\begin{array}{c}\text { Number of } \\
\text { Moles of MCA }\end{array}$ & $\begin{array}{c}\text { Weight Ratio of } \\
\text { MCA to Cellulose }\end{array}$ & $\begin{array}{c}\text { Mole Ratio of MCA } \\
\text { to Cellulose }\end{array}$ & $\begin{array}{c}\text { Degree of } \\
\text { Separation }\end{array}$ \\
\hline 2.5 & 0.046 & 0.18 & 0.215 & 0.12 \\
\hline 5.0 & 0.093 & 0.25 & 0.43 & 0.21 \\
\hline 10 & 0.106 & 0.50 & 0.86 & 0.25 \\
\hline 20 & 0.212 & 1.00 & 1.70 & 0.39 \\
\hline 30 & 0.317 & 1.50 & 2.58 & 0.311 \\
\hline
\end{tabular}

Despite the positive results obtained when using procedure $\mathrm{C}$, the large quantities of $\mathrm{NaOH}$ and MCA needed to obtain the desired DS made it a non-feasible approach. As mentioned previously, the large amounts of MCA used in the reaction are partly consumed by the side reaction (Fig. 2). Carrying out the reaction in a solvent other than water, which does not hydrolyze MCA, can minimize the competing side reaction. Isopropyl alcohol is an acceptable choice for this task, since it is safe, available, and cheap. For this method, the pulp sample in sheet form was pre-steeped in a $16 \% \mathrm{NaOH}$ solution at room temperature, and the excess $\mathrm{NaOH}$ was removed by a press. A solution of MCA in isopropyl alcohol was applied onto the pulp via spraying. The treated pulp was shredded then heated at $70{ }^{\circ} \mathrm{C}$ for $30 \mathrm{~min}$. As can be seen from the results summarized in Table 4, CM-pulp with a wide range of DS can be obtained. It is evident from the results that the amount of MCA added is the dominant factor in the carboxymethylation reaction under these reaction conditions, and time is much less of a factor (Table 4). It is also interesting to note that when the mole ratio of MCA to $\mathrm{NaOH}$ exceeded 1.0, the degree of substitution decreased. This could be related to the acid-base reaction between $\mathrm{NaOH}$ and MCA (Fig. 2). Since at high concentrations of MCA, most of the sodium hydroxide needed to activate the hydroxyl groups in the cellulose for nucleophilic substitution are consumed. Therefore, a CM-pulp with a low DS is produced. The IVs of the CM-pulps ranged from $10.7 \mathrm{~d} / \mathrm{g}$ to $11.2 \mathrm{~d} / \mathrm{g}$.

Table 4. Carboxymethylation of Pulp in Isopropyl Alcohol

\begin{tabular}{|c|c|c|c|c|}
\hline $\begin{array}{c}\text { Weight of MCA } \\
(\mathrm{g})\end{array}$ & $\begin{array}{c}\text { Number of } \\
\text { Moles of MCA }\end{array}$ & $\begin{array}{c}\text { Weight Ratio of } \\
\text { MCA to Cellulose }\end{array}$ & $\begin{array}{c}\text { Mole Ratio of } \\
\text { MCA to } \\
\text { Cellulose }\end{array}$ & $\begin{array}{c}\text { Degree of } \\
\text { Separation }\end{array}$ \\
\hline 2.5 & 0.046 & 0.18 & 0.215 & 0.11 \\
\hline 5.0 & 0.093 & 0.25 & 0.43 & 0.19 \\
\hline 10 & 0.106 & 0.50 & 0.86 & 0.29 \\
\hline 20 & 0.212 & 1.00 & 1.70 & $>0.39$ \\
\hline 30 & 0.317 & 1.50 & 2.58 & 0.284 \\
\hline 40 & 0.423 & 2.00 & 3.40 & 0.041 \\
\hline
\end{tabular}

\section{CMHPMC Properties}

The preparation of CMHPMC from CM-pulp was carried out using a solvent-free process. The same reaction conditions were applied as preparing a reference sample of HMPC from Ethenier-F-HV. The process involved first converting CM-pulp to cellulose alkoxide by reacting it with excess $50 \%$ solution of $\mathrm{NaOH}$, as shown in Fig. 3a. The activated pulp then reacted with a mixture of chloromethane and propylene oxide as shown in Fig. 3a. The amount of chloromethane and propylene oxide were selected to prepare HPMC with a degree of substitution that matches that of the commercial HPMC. The 
methyl and hydroxypropyl content of CMHPMC were determined as described by (Vieira et al. 2007). The methoxyl and hydroxypropyl contents were about $28 \%$ and $8 \%$ $( \pm 2 \%)$, respectively.

Larger exotherms were observed in the CM-pulp compared to the control pulp (Ethenier-F-HV) during the preparation of cellulose ethers in the Parr reactor. The magnitude of the exotherm appeared to correlate with the DS of the CM-pulp. Such behavior indicated a more reactive pulp. Lower amounts of reactants needed for the etherification process was one possible benefit of this preparation method. The FT-IR spectrum of CMHPMC prepared from CM-pulp with a DS of 0.15 is shown in Fig. 3b. The spectrum shows a broad strong peak at $3450 \mathrm{~cm}^{-1}$, which corresponded to the $\mathrm{O}-\mathrm{H}$ stretching of the alcohol and carboxylate groups. The multiple peaks extending from 2795 $\mathrm{cm}^{-1}$ to $2935 \mathrm{~cm}^{-1}$ corresponded to the $\mathrm{C}-\mathrm{H}$ stretching of the alkyl groups. The peak at $1615 \mathrm{~cm}^{-1}$ could be related to the $\mathrm{C}=\mathrm{O}$ of the carboxylate groups. The strong band at 1025 $\mathrm{cm}^{-1}$ could be attributed to the stretching frequency of $\mathrm{C}-\mathrm{O}-\mathrm{C}$ and $\mathrm{C}-\mathrm{O}$ of the ethers and alcohols.

A summary of the selected physical properties of the HPMC control and CMHPMC samples as a function of DS is shown in Table 5. The results show that, DS of the CM-pulp has small effect on turbidity, insoluble content, and viscosity.
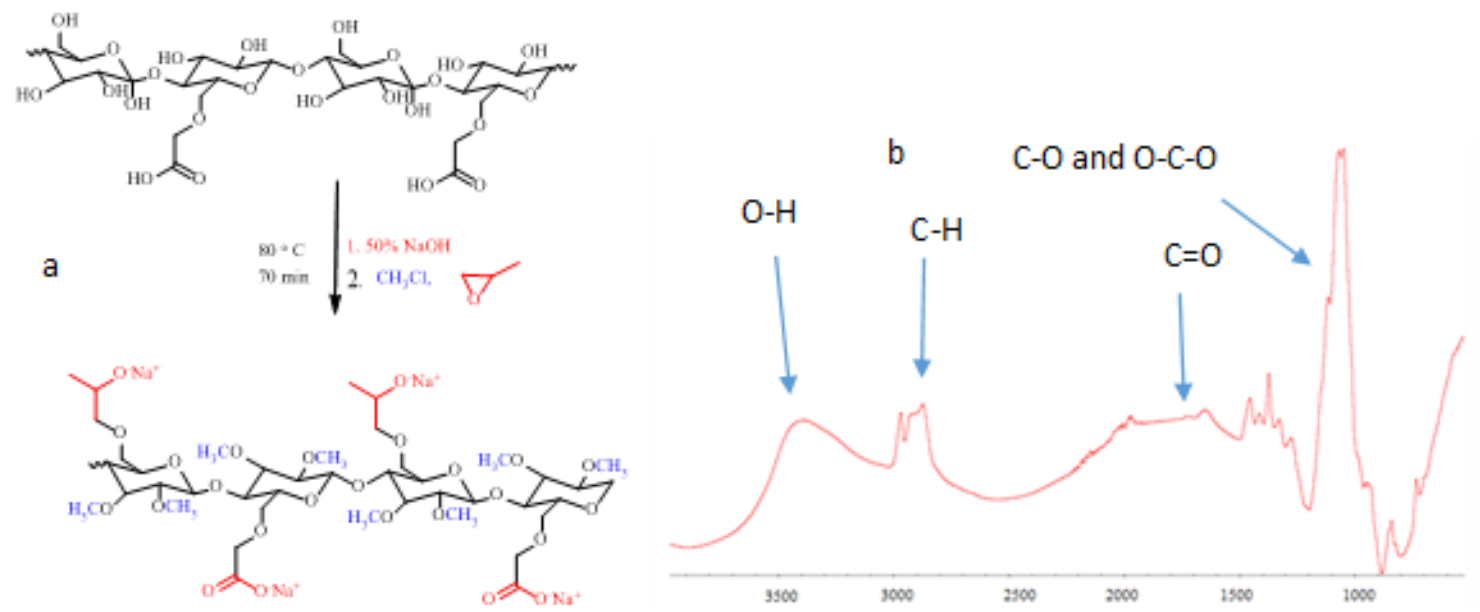

Fig. 3. The (a) conversion of CM-pulp to CHHPMC and (b) FT-IR of CMHPMC

Table 5. A Summary of the Selected Physical Properties of the HPMC Control and CMHPMC Samples

\begin{tabular}{|c|c|c|c|}
\hline $\begin{array}{l}\text { Degrees of substitution of the CM- } \\
\text { pulp Used in Making CMHPMC }\end{array}$ & $\begin{array}{l}\text { Turbidity } \\
\text { (NTU) }\end{array}$ & Insolubles (wt\%) & $\begin{array}{l}\text { Viscosity } \\
(\mathrm{cP})^{3}\end{array}$ \\
\hline HPMC (control) & 5.3 & 3.7 & 14,300 \\
\hline 0.041 & 4.8 & 2.9 & 14,550 \\
\hline 0.08 & 4.5 & 2.8 & 15,110 \\
\hline 0.15 & 3.7 & 2.3 & 15,050 \\
\hline
\end{tabular}




\section{Rheological Properties}

The rheological (viscosity) behavior of the prepared HPMC (control) and CMHPMC samples were investigated. The analysis was performed on a $2 \%$ gel solution. The collected results are summarized in Tables 6 and 7. The solution viscosity was found to increase as the amount of $\mathrm{NaOH}$ used decreased. The highest increase was shown when the $\mathrm{NaOH}$ to pulp ratio was 0.69 (36\% higher than the control HPMC sample, Table 7), but this inversely effected the insoluble and turbidity. The increase in the viscosity could be due to the increase in the intermolecular cross-linking between the cellulose chains (ester and hydrogen bonds), which increases as the carboxyl content increases.

Table 6. Summary of the Selected Rheological Properties of the HPMC control and CMHPMC Samples

\begin{tabular}{|c|c|c|}
\hline $\begin{array}{c}\text { Degrees of substitution of the CM-pulp } \\
\text { Used in Making CMHPMC }\end{array}$ & $\begin{array}{c}\text { Storage Modulus } \\
\left(\mathrm{G}^{\prime}, \mathrm{Pa}\right)\end{array}$ & $\begin{array}{c}\text { Thermal Gelation } \\
\text { Temperature }\left({ }^{\circ} \mathrm{C}\right)\end{array}$ \\
\hline HPMC (control) & 74 & 70 \\
\hline 0.041 & 75 & 85 \\
\hline 0.08 & 61 & 67 \\
\hline 0.15 & 75 & 63 \\
\hline
\end{tabular}

Note: All reactions were carried out at constant concentrations of $\mathrm{MeCl}$ and propylene oxide. In all runs the weight ratio and the mole ratio of $\mathrm{NaOH}$ to pulp were 0.98 and 4.0 , respectively.

Table 7. Effect of Decreasing the Amount of $\mathrm{NaOH}$ on Various Characteristic Parameters of CMHPMC samples with a DS of 0.15

\begin{tabular}{|c|c|c|c|c|c|}
\hline $\begin{array}{c}\text { Weight Ratio of } \\
\text { NaOH to Pulp }\end{array}$ & $\begin{array}{c}\text { Turbidity } \\
(\mathrm{NTU})\end{array}$ & $\begin{array}{c}\text { Insoluble } \\
(\text { wt.\%) }\end{array}$ & $\begin{array}{c}\text { Storage } \\
\text { Modulus } \\
\left(G^{\prime}, \mathrm{Pa}\right)\end{array}$ & $\begin{array}{c}\text { Thermal } \\
\text { Gelation } \\
\left({ }^{\circ} \mathrm{C}\right)\end{array}$ & $\begin{array}{c}\text { Viscosity } \\
(\mathrm{cp})\end{array}$ \\
\hline 0.98 & 4.8 & 2.9 & 75 & 85 & 15050 \\
\hline 0.79 & 5.5 & 3.2 & 72 & 85 & 17140 \\
\hline 0.69 & 6.1 & 4.1 & 80 & 86 & 20480 \\
\hline
\end{tabular}

An increase in the viscosity was also observed as the amount of sodium hydroxide added was decreased. The possible reasons for this are as follows: (1) with less $\mathrm{NaOH}$, the amount of cellulose ether degradation was lower, and therefore a product with a higher MW was produced; (2) the competing side reactions shown in Figs. 4a and $4 \mathrm{~b}$ were minimized in the presence of less $\mathrm{NaOH}$, and as a result of that cellulose ethers with a higher D. S. and higher viscosity were produced. In reaction $4 \mathrm{a}, \mathrm{NaOH}$ undergoes a nucleophilic substitution reaction with methyl chloride to form methanol. In reaction $4 \mathrm{~b}$ the other starting material propylene oxide reacts with $\mathrm{NaOH}$ to form the side product propylene diol (Table 7).

Lowering the amount of $\mathrm{NaOH}$ slightly affected the insolubles and the turbidity.

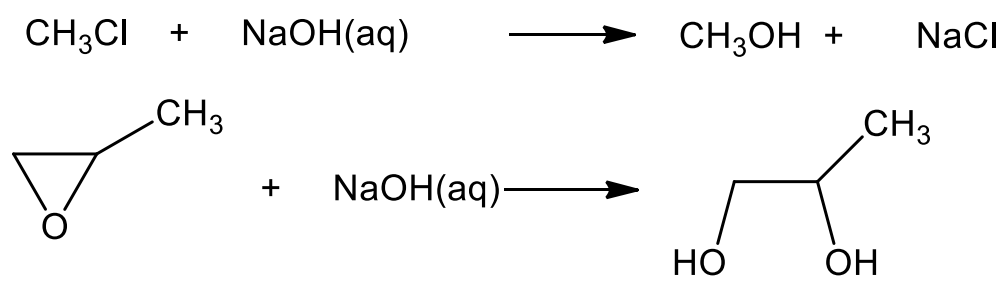

Fig. 4. Competing side reactions (a) and (b) 


\section{Thermal Gelation Temperature.}

The complex viscosity, storage modulus, and loss modulus were all measured for the prepared CMHPMC and control HPMC samples. As mentioned above, all these factors decreased as the temperature increased. The inflection point where the three parameters begin to rapidly decrease with the increase in temperature is the onset of cellulose ether precipitation from solution (as shown in Fig. 5).

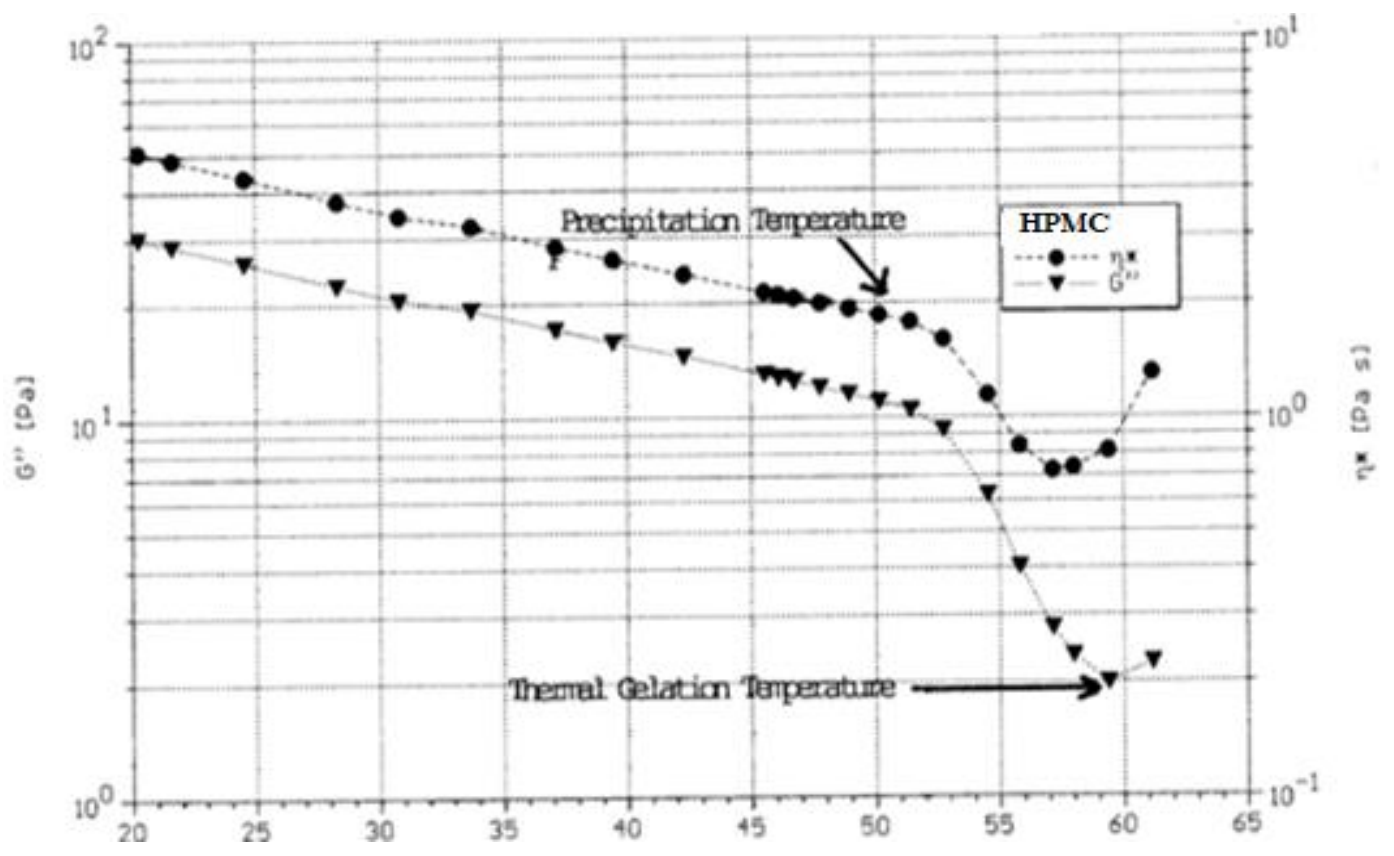

Fig. 5. The viscosity-temperature response of the control HPMC sample ( $2 \%$ solution), the incipient precipitation temperature at approximately $52^{\circ} \mathrm{C}$, and the thermal gelation temperature at $57^{\circ} \mathrm{C}$

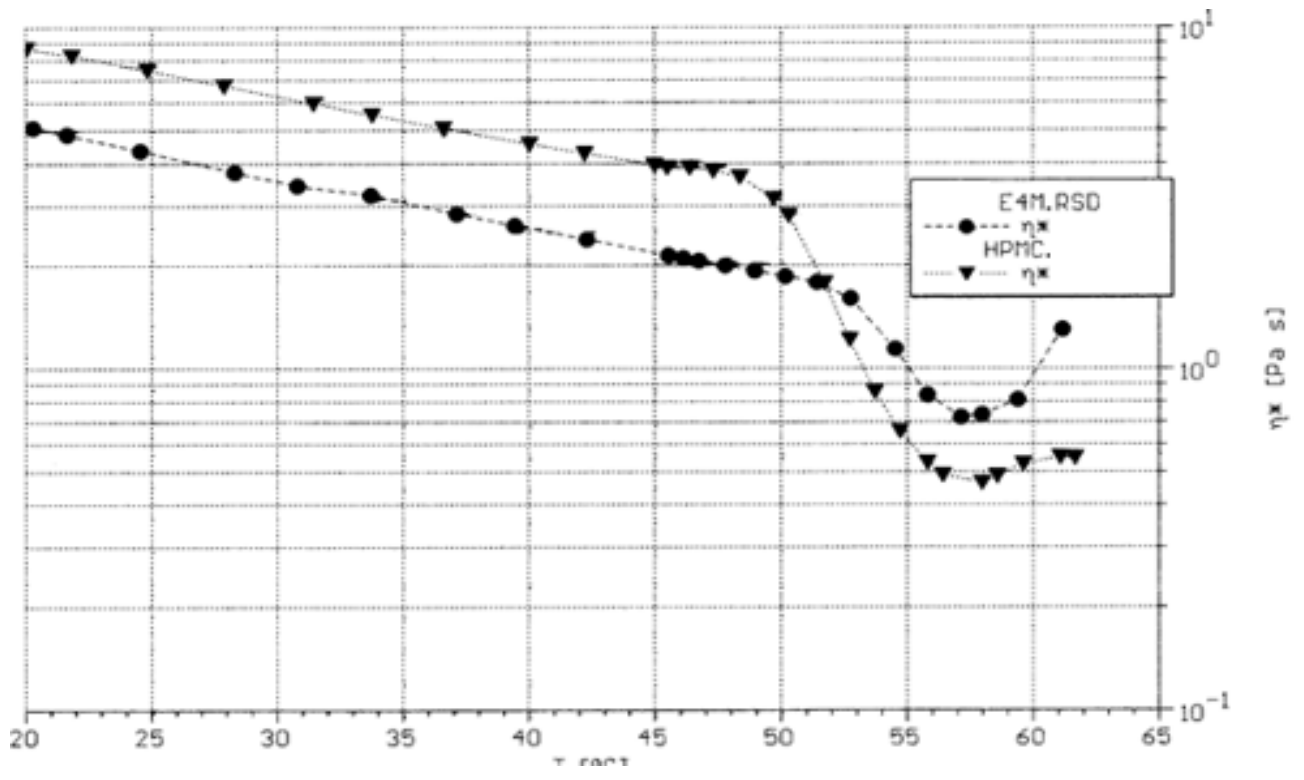

Fig. 6. Comparison of temperature response of Methocel E4M and control HPMC 
The thermal study was first performed on commercial HPMC produced by the Dow Chemical Company and sold under the trade name E4M (the methoxyl content was $28 \%$ to $30 \%$ and the hydroxypropyl content was $7 \%$ to $12 \%$ ). The results are shown in Fig. 5 (Dow Chemical Company 2020), where the onset of precipitation begins at approximately $52{ }^{\circ} \mathrm{C}$, with thermal gelation occurring at $55^{\circ} \mathrm{C}$. For the control HPMC sample prepared from Ethenier-F-UHV, the onset of precipitation starts at approximately $49{ }^{\circ} \mathrm{C}$, with thermal gelation also occurring at $55^{\circ} \mathrm{C}$ (as shown in Fig. 6). Thus, the precipitation and thermal gelation behavior of the experimental HPMC sample mirrors that of the commercial sample.

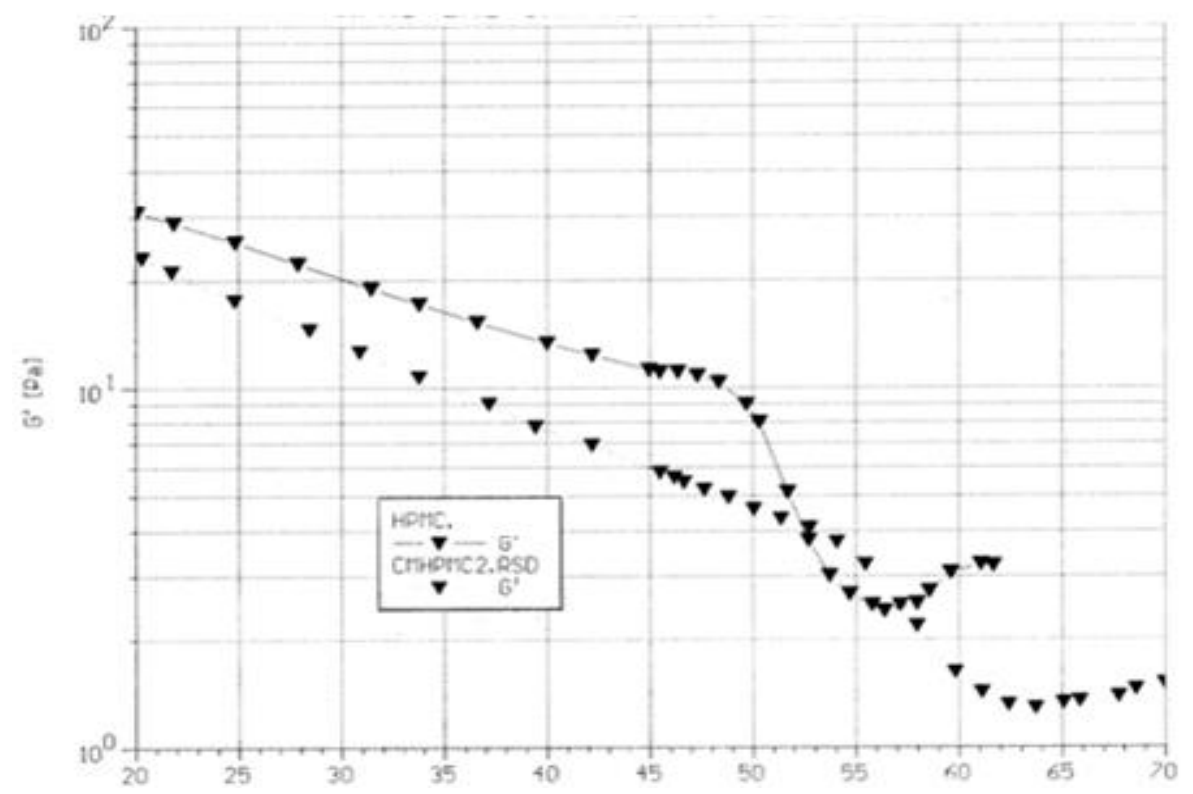

Fig. 7. Storage Moduli of control HPMC and CMHPMC produced form CM-pulp with DS of 0.04

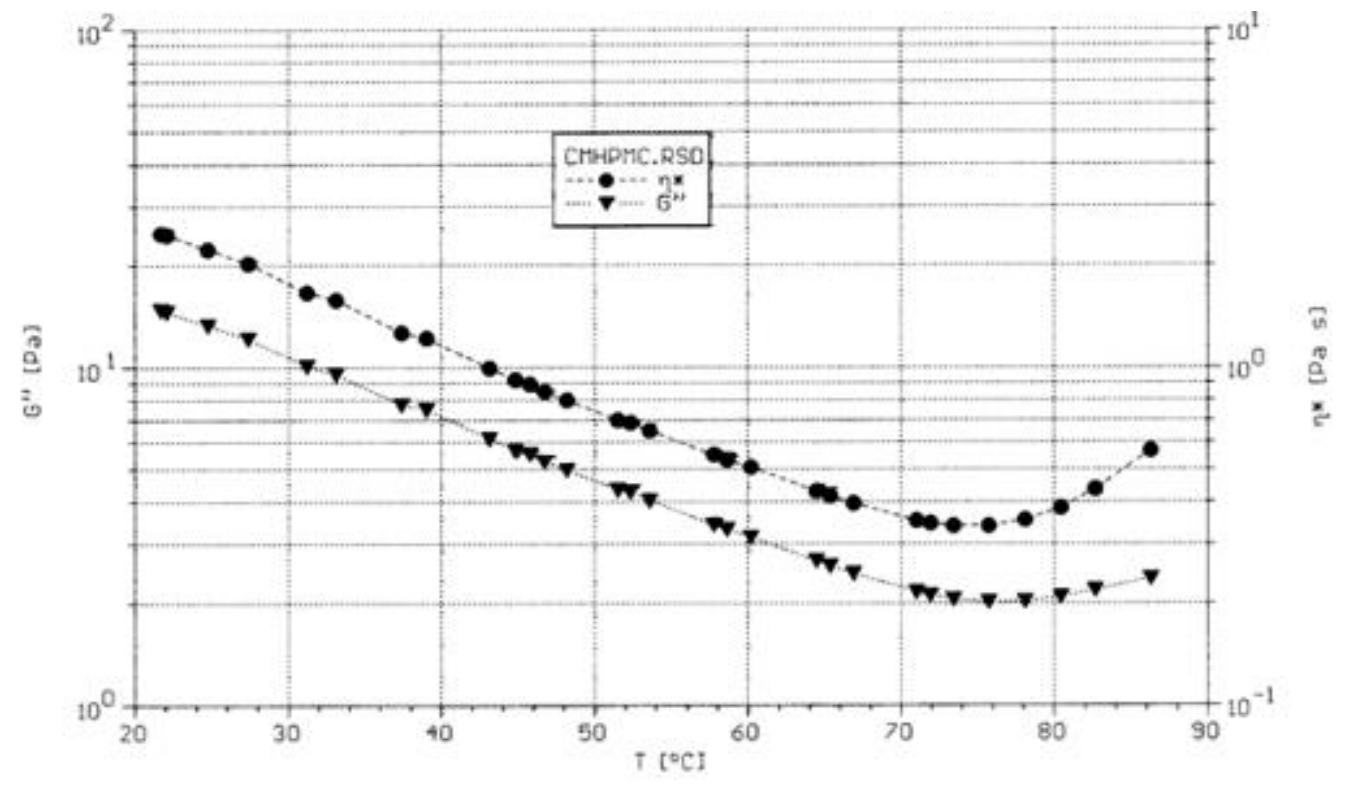

Fig. 8. Thermal gelation of CMHPMC produced form CM-pulp with DS of 0.15 , gelation temperature is $83^{\circ} \mathrm{C}$ 
For the CMHPMC sample containing an initial CM-content of 0.04 D. S., a temperature response (as shown in Fig. 7) was obtained, where the storage modulus $\left(G^{\prime}\right.$, $\mathrm{Pa}$ ) is plotted against the temperature. The precipitation temperature had been extended to approximately $54{ }^{\circ} \mathrm{C}$ and a gelation temperature to approximately $64{ }^{\circ} \mathrm{C}$. Thus, a lower number of ionic groups on the cellulose backbone greatly enhances the solvation of the polymer.

For a CMHPMC sample containing a carboxymethyl content with $0.15 \mathrm{DS}$, no precipitation occurred, since there was no inflection point in the loss modulus (as shown in Fig. 7). However, thermal gelation still takes place at approximately $75{ }^{\circ} \mathrm{C}$ due to the associative effects of methoxyl.

Thus, it is possible to retain the associative nature of cellulose ethers through the presence of methoxyl groups and prevent precipitation of the polymer through the introduction of carboxymethyl (ionic) groups.

\section{CONCLUSIONS}

1. Carboxymethylated pulps with a wide range of carboxyl contents were successfully prepared using various methods.

2. The efficiency of the carboxymethylation reaction was greatly enhanced by replacing the water with isopropyl alcohol as the solvent for monochloroacetic acid (MCA).

3. When isopropyl alcohol was used as a solvent, the carboxymethylated pulp (CMpulp) with the desired degree of substitution (DS) was obtained with less caustic and less MCA.

4. The simplicity and the low amount of chemicals needed to produce the desired CMpulp made this method (using isopropyl alcohol as the solvent) appropriate for the large-scale production of CM-pulp.

5. The carboxymethyl-hydroxypropylmethyl cellulose (CMHPMC) produced from pulp modified with carboxymethyl groups exhibited unusual rheological properties, as illustrated by the greater thermal gelation temperatures, viscosities, and storage moduli.

6. These results make this new generation of cellulose ethers superior for many industrial applications in hot and cool climates.

\section{ACKNOWLEDGEMENTS}

The authors thank the Rayonier Advanced Material Company (Jesup, GA, USA) for providing the pulp used in this work. The authors would also like to acknowledge the An-Najah National University in Palestine for the financial support. 


\section{REFERENCES CITED}

Abushammala, H., and Mao, J. (2019). "A review of the surface modification of cellulose and nanocellulose using aliphatic and aromatic mono- and di-isocyanates," Molecules 24(15), 2782-2800. DOI: 10.3390/molecules24152782

Akindoyo, J. O., Beg, M. D. H., Ghazali, S., Islam, M. R., Jeyaratnam, N., and Yuvaraj, A. R. (2016). "Polyurethane types, synthesis and applications - A review," RSC Advances 6(115), 114453-114482. DOI: 10.1039/C6RA14525F

Arca, H. C., Mosquera-Giraldo, L. I., Bi, V. Xu, D., Taylor, L. S., and Edgar, K. J. (2018). "Pharmaceutical applications of cellulose ethers and cellulose ether esters," Biomacromolecules 19(7), 2351-2376. DOI: 10.1021/acs.biomac.8b00517.

Bajpai, P. (1999). "Application of enzymes in the pulp and paper industry," Biotechnology Progress 15(2), 147-157. DOI: 10.1021/bp990013k

Bochek, A. M. (2003). "Effect of hydrogen bonding on cellulose solubility in aqueous and nonaqueous solvents," Russian Journal of Applied Chemistry 76(11), 1711-1719. DOI: 10.1023/B:RJAC.0000018669.88546.56

Cao, Y., and Tan, H. (2006). "Improvement of alkali solubility of cellulose with enzymatic treatment," Applied Microbiology and Biotechnology 70(2), 176-182. DOI: 10.1007/s00253-005-0069-8

Dow Chemical Company (2020). "Using METHOCEL cellulose ethers for controlled release of drugs in hydrophilic matrix systems," (https://www.colorcon.com/productsformulation/all-products/download/677/2063/34?method=view). Accessed.

Engström, A.-C., Ek, M., and Henriksson, G. (2006). "Improved accessibility and reactivity of dissolving pulp for the viscose process: Pretreatment with monocomponent endoglucanase," Biomacromolecules 7(6), 2027-2031. DOI: $10.1021 / \mathrm{bm} 0509725$

Heinze, T., and Liebert, T. (2012). “10.05 - Celluloses and polyoses/hemicelluloses,” in: Polymer Science: A Comprehensive Reference Volume 10: Polymers for a Sustainable Environment and Green Energy, K., Matyjaszewski, and M, Möller (ed.), Elsevier, Amsterdam, Netherlands, pp. 83-152.

Heinze, T., Koschella, A., Liebert, T., Harabagiu, V., and Coseri, S (2012). "Cellulose: chemistry of cellulose derivatization," in: The European Polysaccharide Network of Excellence (EPNOE), P. Navard (ed.), Springer Nature Switzerland AG, Cham, Switzerland, pp. 283-327.

Henriksson, G., Christiernin, M., and Agnemo, R. (2005). "Monocomponent endoglucanase treatment increases the reactivity of softwood sulphite dissolving pulp," Journal of Industrial Microbiology and Biotechnology 32(5), 211-214. DOI: 10.1007/s10295-005-0220-7

Iovleva, M. M., Smirnova, V. N., Belousova, T. A., Banduryan, S. I., Kalashnik, A. T. and Rudlnskaya, G. Y. (1996). "Some properties of activated mixtures of cellulose with solid sodium hydroxide," Fibre Chemistry 28(5), 347-350. DOI: 10.1007/bf01057704

ISO 5351-1:1981 (1981). "Cellulose in dilute solutions - Determination of limiting viscosity number - Part 1: Method in cupri-ethylene-diamine (CED) solution," International Organization for Standardization, Geneva, Switzerland.

Isogai, A., Onabe, F., and Usuda, M. (1992). "Swelling behavior of cellulose by chemical and mechanical treatments," Sen'i Gakkaishi 48(9), 487-492. DOI:

10.2115/fiber.48.9_487 
Krässig, H. A. (1993). Cellulose - Structure, Accessibility and Reactivity. Polymer Monographs Volume 11, Gordon and Breach Science Publishers, New York, NY.

Kunze, J., and Fink, H.-P. (2005). "Structural changes and activation of cellulose by caustic soda solution with urea," Macromolecular Symposia 223(1), 175-187. DOI: $10.1002 /$ masy.200550512

Lin, L. (2002). "Thermal gelation of methylcellulose in water: Scaling and thermoreversibility," Macromolecules 35(15), 5990-5998. DOI: 10.1021/ma0201781

Mantanis, G. I., Young, R. A., and Rowell, R. M. (1995). "Swelling of compressed cellulose fiber webs in organic liquids," Cellulose 2(10), 1-22. DOI: 10.1007/BF00812768

Petzold-Welcke, K., Michaelis, N., and Heinze, T. (2009). "Unconventional cellulose products through nucleophilic displacement reactions," Macromolecular Symposia 280(1), 72-85. DOI: 10.1002/masy.200950609

Rahkamo, L., Siika-Aho, M., Vehviläinen, M., Dolk, M., Viikari, L., Nousiainen, P., and Buchert, J. (1996). "Modification of hardwood dissolving pulp with purified Trichoderma reesei cellulases," Cellulose 3(3), 153-163. DOI: 10.1007/BF02228798

Sango, C., Kaur, P., Bhardwaj, N. K., Sharma, J. (2018). "Bacterial cellulase treatment for enhancing reactivity of pre-hydrolysed kraft dissolving pulp for viscose," Biotech; 8(6), 271. doi: 10.1007/s 13205-018-1293-0

Sarkar, N. (1977). "Thermal gelation properties of methyl and hydroxypropyl methylcellulose," Journal of Applied Polymer Science 24(4), 1073-1087. DOI: 10.1002/app.1979.070240420

Silva, S. M. C., Pinto, F. V., Antunes, F. E., Miguel, M. B., Sousa, J. J. S., and Pais, A. A. C. C. (2008). "Aggregation and gelation in hydroxypropylmethyl cellulose aqueous solutions," Journal of Colloid and Interface Science (327(2), 333-340. DOI: 10.1016/j.jcis.2008.08.056

Siró, I. and Plackett, D. (2010). "Microfibrillated cellulose and new nanocomposite materials: A review," Cellulose 17, 459-494. DOI: 10.1007/s10570-010-9405-y

TAPPI T237 cm-08. (2008). "Carboxyl content of pulp Test," TAPPI Press, Atlanta, GA.

Tosh, B. (2014). "Synthesis and sustainable applications of cellulose esters and ethers: A review," International Journal of Energy, Sustainability and Environmental Engineering 1(2), 56-78.

Vieira, R. G. P., Rodrigues F. G., Assunção, R. M. N., Meireles, C. S., Vieira, J. G., and Oliveira, G. S. (2007). "Synthesis and characterization of methylcellulose from sugar cane bagasse cellulose," Carbohydr. Polym. 67(2), 182-189. DOI: 10.1016/j.carbpol.2006.05.007

Zhao, H., Kwak, J. H., Wang, W., Franz, J. A., White, J. M and Holladay, J. E. (2006). "Effects of crystallinity on dilute acid hydrolysis of cellulose by cellulose ball-milling study," Energy \& Fuels 20(2), 807-811. DOI: 10.1021/ef050319a

Article submitted: September 4, 2020; Peer review completed: November 21, 2020; Revised version received and accepted: January 1, 2021; Published: January 7, 2021. DOI: 10.15376/biores.16.1.1453-1468 